\title{
Morphometric parameters and histological study of the filum terminale of adult human cadavers and magnetic resonance images
}

\author{
A.Y. Nasr ${ }^{1,2}$, A.M. Hussein ${ }^{1}$, S.A. Zaghloul ${ }^{1}$ \\ ${ }^{1}$ Anatomy Department, Faculty of Medicine, King Abdulaziz University. Jeddah, Kingdom of Saudi Arabia \\ ${ }^{2}$ Anatomy Department, Faculty of Medicine, Zagazig University, Zagazig, Egypt
}

[Received: 7 March 2018; Accepted: 10 April 2018]

Background: Morphology and histology of filum terminale (FT) has a role in the pathophysiology of tethered cord syndrome (TCS). This research was implemented to investigate the morphometric parameters and histological structure of normal FT in adult human cadavers and magnetic resonance imaging (MRI) scans to correlate them with the pathophysiology of TCS.

Materials and methods: Twenty five adult human cadavers (15 males, 10 females) and $100 \mathrm{MRI}$ echo scans of lumbosacral region (50 males and 50 females), were used in this study. MRI patients were divided into 21-40 and 41-60 age groups. The cadavers were dissected at the prone position to explore their fila. The length of FT, filum terminale internum (FTI), filum terminale externum (FTE), vertebral level of beginning, dural piercing and termination of FT, and the initial, midpoint, and mid-FTE diameters were determined. Four segments were excised from lower conus, upper, middle, and lower thirds of FT. The specimens were processed for light microscopic examination. Statistical analysis was done for these parameters. Results: MRI morphometrical parameters of FT, except FTI length, revealed no age effect or sex differences, where length of FTI, FTE, initial diameter, level of conus medullaris termination (CMT) and dural sac termination (DST) were $174.1 \pm 16.8,75.8 \pm 9.5,1.6 \pm 0.21, L 1-2$ and $S 2 U$ in males and $166.9 \pm 18.9$, $74.1 \pm 9.3,1.53 \pm 0.25$, L1-2 and S2M vertebrae in females, respectively. However, non-significant sex difference was observed in morphometric parameters of cadaveric FT, where length of FTI and FTE, initial diameter, CMT and DST levels were 164.2 $\pm 11.6,76.7 \pm 8.1,1.7 \pm 0.14, L 1 L$ and $S 2 U$ vertebrae in males and $159.2 \pm 10.1,71.02 \pm 7.3,1.6 \pm 0.29, \mathrm{~L} 1 \mathrm{~L}$ and S2U in females, respectively. Moreover, CMT below $L 2$ vertebra was seen in $5 \%$ of $M R I$ scans and $8 \%$ of cadavers. Also, the initial diameter of FT $>2 \mathrm{~mm}$ was recorded in $7 \%$ of MRI and $8 \%$ of cadaveric cases. Histologically, the structure of FT showed gradual reduction in nervous, glial, and vascular tissues with converse increase in collagen content in FTE compared with those of FTI.

Conclusions: Knowledge of the morphometric parameters and the histological structure of FT are necessary for clinicians who dealing with diagnosis or treatment of tethered cord syndrome. (Folia Morphol 2018; 77, 4: 609-619)

Key words: filum terminale, morphometry, measurements, histology, magnetic resonance imaging, adult, cadavers

Address for correspondence: Dr. A.Y. Nasr; Anatomy Department, Faculty of Medicine, Zagazig University, Egypt and King Abdulaziz University, Jeddah, KSA; P.O. Box 80205, Jeddah 21589, Kingdom of Saudi Arabia, tel: 00966 (12) 6401000, ext. 20477, fax: 00966(12)6401000, ext. 20121, e-mail: ashrafnaeem2013@gmail.com; ashrafnaeem2013@yahoo.com 


\section{INTRODUCTION}

The filum terminale (FT) is a fibrovascular structure connecting the conus medullaris to coccyx [21]. Its development begins from $8^{\text {th }}$ week of gestation, through spinal cord involution. Where, from $8^{\text {th }}$ to $25^{\text {th }}$ gestational week, the vertebral column exhibits higher growth rate than that of spinal cord. So, the site of conus medullaris is elevated upward, while at birth the level of conus medullaris termination (CMT) become opposite T12-L2 vertebrae. Thereafter, in adult, the mean level of CMT lies at the lower border of L1 and that of dural sac termination (DST) lies at S2 vertebra [13].

Morphology and structure of FT play a great role in pathophysiology of tethered cord syndrome (TCS) in persons who have normal CMT level [23], where degradation of collagen fibres, vascular structure, increase adipose tissue and hyalinisation are seen in adult FT of TCS, not in foetal samples $[16,25]$. Also, the elastic fibres are seen in TCS specimens and the adult cadaver. Meanwhile, ependymal cells, ganglion cells and peripheral nerves are seen in foetal FT samples [23]. Low content of elastic fibres with high content of fat and fibrous structure within the FT can render FT inappropriately tense with subsequent generation of TCS [9]. Low-position of conus, increase initial diameter and fibrous content of FT could induce TCS [7].

Variable cadaveric and imaging studies have been carried out to determine the anatomical position of CMT and DST in population in different parts of the world [3]. Magnetic resonance imaging (MRI) being a nonionising, noninvasive method allows better visualisation of parenchyma and adjacent soft-tissue structures of spinal cord [22]. Dural sac is usually observed to terminate at the level of S2 vertebral body [1]. Studies have reported variations in the position of conus medullaris (CM) and DS in different races [5]. Such variations may contribute to compromise in safety of various diagnostic and therapeutic procedures [14].

Tethered cord syndrome occurs as a result of decrease elasticity of FT with subsequent tethering and traction on conus. This syndrome is diagnosed by neurological, urological and orthopaedic malfunction [26]. Also, TCS is accompanied by tight filum and low-position of conus below L2 [7].

This study aimed to evaluate the morphometric parameters including the length, initial, midpoint, mid-FT externum (FTE) diameters and vertebral levels of the beginning and site of dural piercing and the his- tological structure of the different part of FT in both adult human cadavers and sagittal MRI echo scans.

\section{MATERIALS AND METHODS}

Twenty-five adult human cadavers ( 15 males and 10 females) and $100 \mathrm{MRI}$ scans (50 males and 50 females) were used in this study. Gross morphologic parameters, MRI radiologic morphometry, and histological structure of FT were investigated. The height of MRI subjects and the length of the cadavers were measured.

The cadavers were obtained from the Anatomy Department, Faculty of Medicine, King Abdulaziz University. A midline dorsal longitudinal skin and aponeurotic incision was done from the tenth thoracic vertebra down to the coccyx in the prone-positioned cadavers. The spinous processes and laminae were exposed after detachment of the paravertebral muscles. Laminectomy was performed to expose the spinal cord with its surrounding meninges. A midline longitudinal dural incision was done to expose the spinal cord. FT was identified and traced caudally throughout its length (Fig. 1A).

Filum terminale begins where the conus medullaris ends by a tapering part [22]. FT has intradural (FT internum) and extradural (FT externum) parts. FT internum (FTI) extends from the termination of conus medullaris down to its dural piercing level and filum terminale externum (FTE) extends from the dural-piercing level down to the coccyx (Fig. 1B). The levels of the initial point, dural piercing or/and fusion, dural sac termination and termination (DST) of the filum terminale were determined with reference to their corresponding neighbouring vertebral segment (Fig. 1C, D). Length of FTI and FTE, initial diameter (D1), middle diameter (D2), and diameter at the middle of FTE (D3) were measured with a digital Vernier calliper (Fig. 2).

Light microscopic study. Segments (1 cm long) from CM, upper, middle, and lower thirds of each FT were transversely sectioned for histological study. These segments were immersed in $10 \%$ formalin for $48 \mathrm{~h}$ followed by phosphate buffer solution (PBS) for $24 \mathrm{~h}$. Then, the segments were processed for light microscopic examination. 3-5- $\mu$ m-thick sections of each segment were stained with haematoxylin and eosin, Masson's trichrome, and Silver stains to analyse their histological structure [2].

One hundred MR lumbosacral sagittal echo scans of 50 normal males and 50 normal females were used 

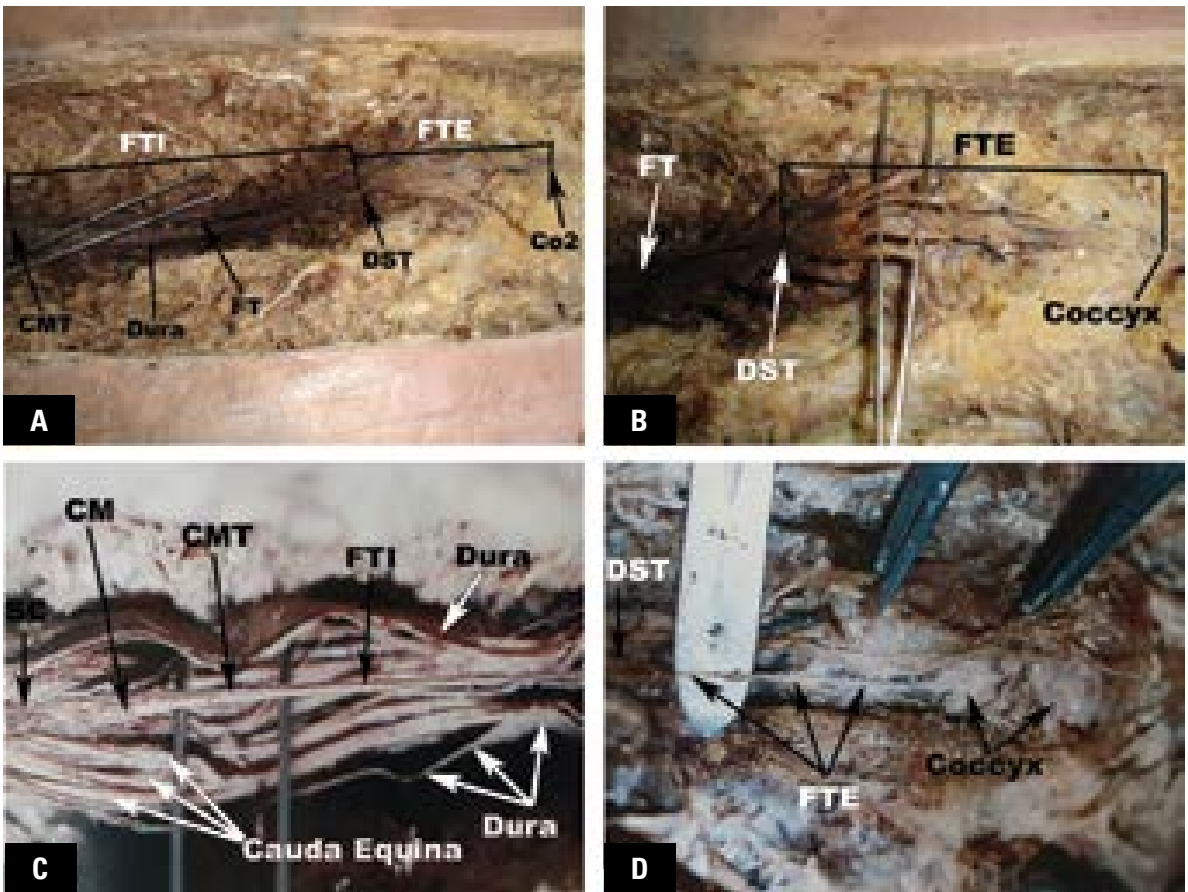

Figure 1. Photographs of human cadaveric specimens showing; A. The lower dorsal aspect of an adults human cadaver after laminectomy showing the vertebral canal containing open dura mater (Dura) and its contents. The filum terminale (FT) appears as a mid-line fibrous band extending from the lower end of conus medullaris (CMT) to the back of second coccygeal segment (Co2). FT has intradural part (FTI) extending from CMT to the lower end of dural sac (DST) and extra-dural part (FTE) extending from DST to Co2; $\mathbf{B}$. The cadaveric specimen shows the filum terminale externum (FTE); C. The cadaveric specimen shows an opened dural sac (Dura) containing conus medullaris (CM) and its termination (CMT) surrounded by the nerves forming the cauda equina. The intradural part (FTI) extends from the CMT at the middle of the cauda equine; D. A cadaveric specimen shows the extradural part of filum terminale extending (FTE) from DST down to the coccyx.
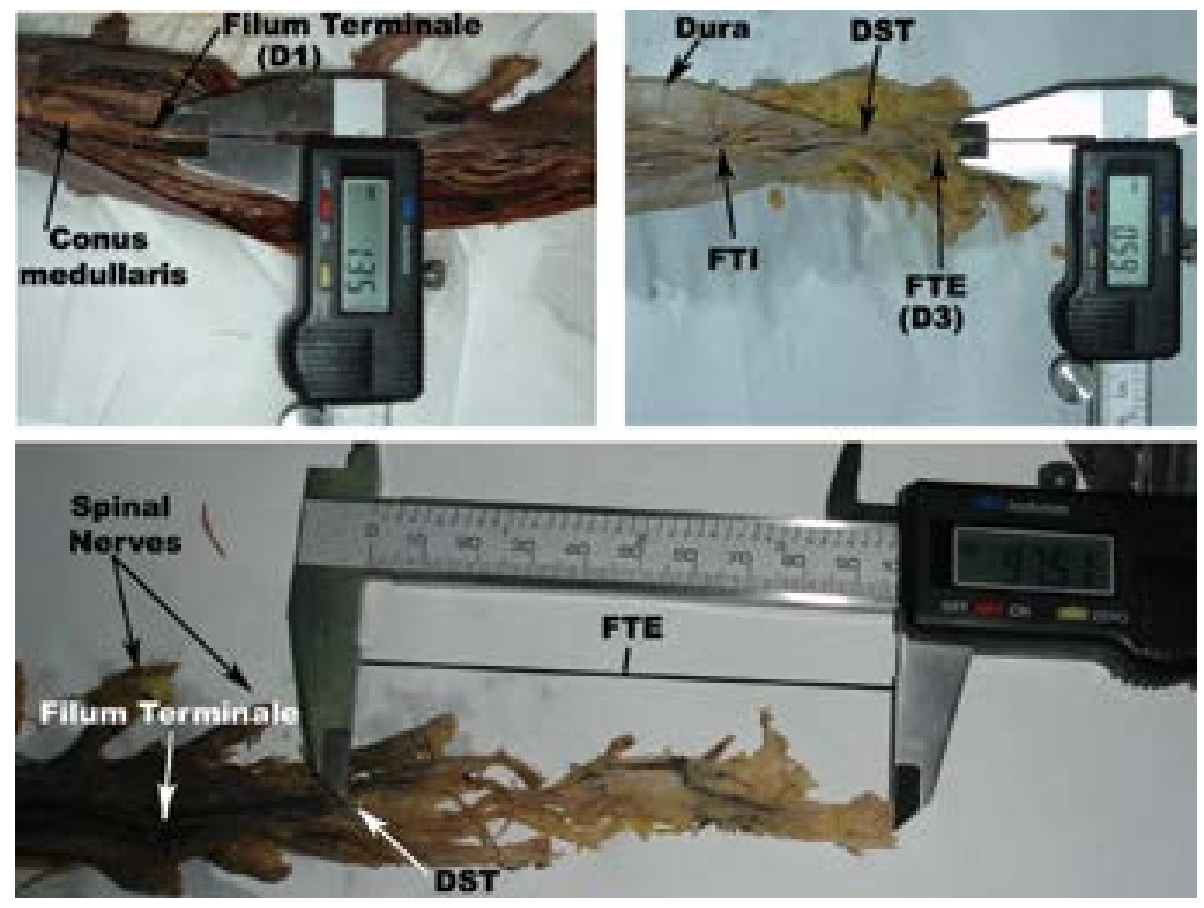

Figure 2. Photographs of cadaveric specimens showing methods of measurement of the morphometric parameters of filum terminale; FTI intradural part of filum terminale; FTE — extradural part of filum terminal; D1 — initial diamter of filum terminale; D3 — diameter at mid-FTE; DST — dural sac termination level; CMT — conus medullaris termination (beginning of filum terminale). 

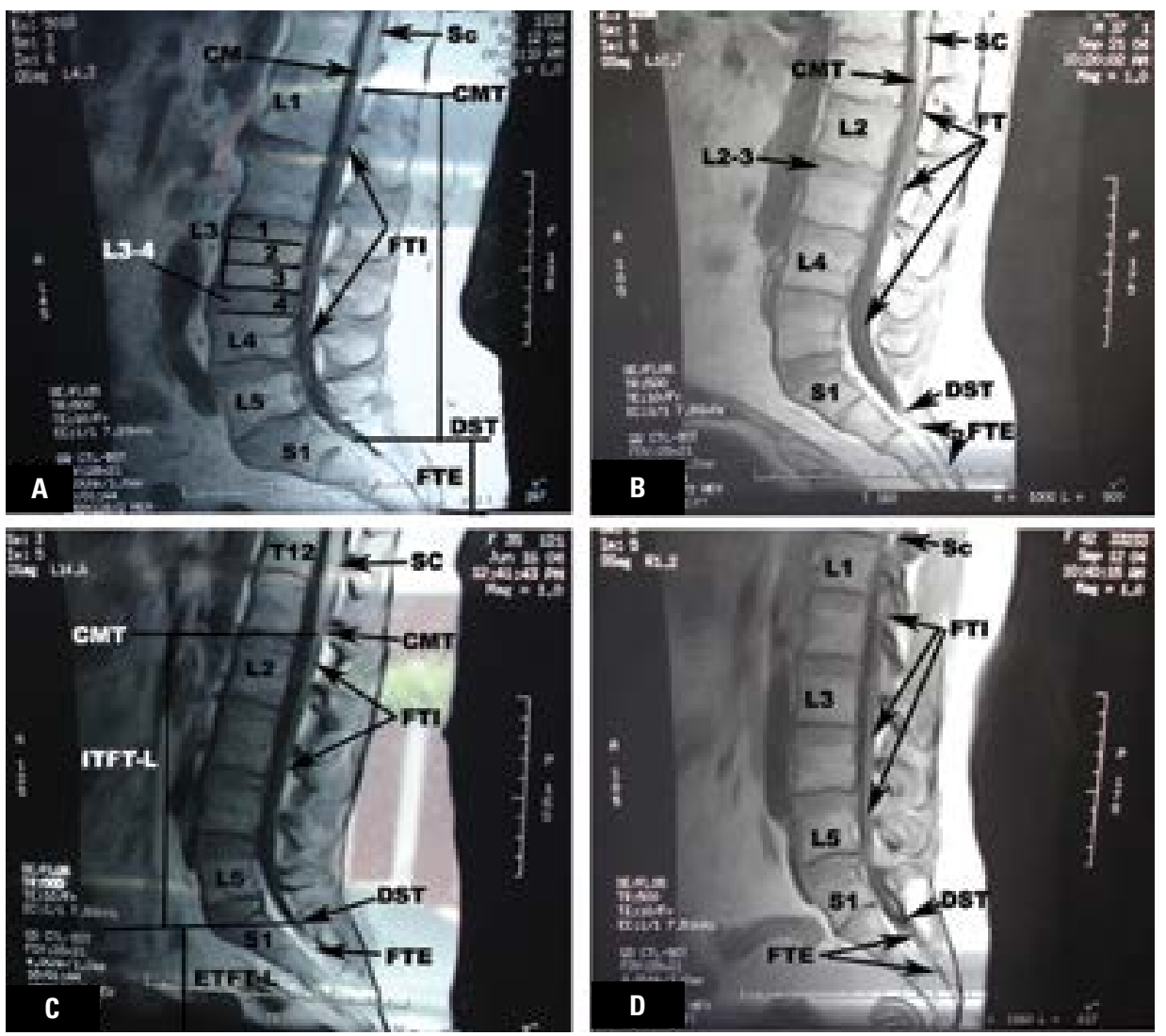

Figure 3. A. Magnetic resonance imaging (MRI) sagittal echo scan showing the different parts $(1,2,3)$ of a vertebra (L3) and intervertebral disc (4) that use as a numerical variable for the method of determination of the vertebral level of conus medullaris termination (CMT), initiation of filum terminale (FT), dural sac termination (DST), length of intradural filum (FTI), length of extradural filum (FTE); B-D. MRI scans showing different levels of initiation of filum terminale (CMT), dural piercing level (DST), length of intradural (FTI) and extradural (FTE) segments in male and female persons of different age groups.

in this study. The study population comprised people aged 21-60 years without any apparent effect of the skeletal growth and/or the change in position of $\mathrm{CM}$. The persons were chosen from the patients who had been referred for MRI from neurology and neurosurgery outpatient clinics to determine the possible causes of low back pain with or without sciatica. Patients with scoliosis or congenital anomalies of spine were excluded. All patients underwent MRI unit in Radio-diagnostic Department of King Abdulaziz University Hospital. GE Signa 1.5 Tesla MR Machine (GEMS) scanner was used to create sagittal and axial T1- and T2-weighted images of the lumbosacral spines with slice thickness of 4-5 $\mathrm{mm}$, slice interval of $1 \mathrm{~mm}$, TE: 80/EF, echo time, $12 \mathrm{~ms}$, and FOV: $30 \times$ $22.5 \mathrm{~cm}$. All MR scans were taken in supine position. Vertebral level of FT beginning (CMT), dural piercing (DST), length of FT, FTI, FTI, initial, midpoint, mid-FTE diameters were determined (Fig. 3). MRI subjects were classified into two equal age-groups for each sex; 21-40 years and 41-60 years groups.
Each vertebra was divided into three thirds, and the space of intervertebral disc was also considered for this parameter. Horizontal lines were drawn from CMT, DST, and end of FTE levels on midsagittal image at a right-angle on the longitudinal axis of the spine (Fig. 3) [15].

For the purposes of statistical evaluation, the different levels of FT were numbered in an increasing order from upper to lower part, considering three vertebral levels and the intervertebral disc space to be used as variables [15]. Statistical tests, independent t-test and correlation analysis, of variance were performed to reveal difference between groups with covariates of age and sex using SPSS version 22 software for Windows (Chicago, IL, USA). Statistical significance was considered at $p$ value $<0.05$. All data were expressed as mean \pm standard deviation.

Agreement was obtained from Medical Ethical Committee of Faculty of Medicine, King Abdulaziz University, Saudi Arabia before starting the study. 
Table 1. Magnetic resonance imaging measurements of filum terminale in male and female age-groups

\begin{tabular}{|c|c|c|c|c|c|c|}
\hline & \multicolumn{3}{|c|}{ Males } & \multicolumn{3}{|c|}{ Females } \\
\hline & G1 (21-40) & G2 (41-60) & $\mathbf{P}$ & G1 (21-40) & G2 (41-60) & $\mathbf{P}$ \\
\hline Age [year] & $32.6 \pm 6.8$ & $50.4 \pm 7.7$ & $0.001 *$ & $31.7 \pm 6.7$ & $49.1 \pm 5.8$ & $<0.0001^{*}$ \\
\hline Body length [cm] & $171.6 \pm 6.1$ & $168 \pm 5.3$ & $0.03^{*}$ & $164.7 \pm 7.3$ & $163.2 \pm 7.4$ & 0.47 \\
\hline FT-L [mm] & $246.2 \pm 24.4$ & $246.9 \pm 14.6$ & 0.09 & $243.2 \pm 21.2$ & $240.4 \pm 20.4$ & 0.6 \\
\hline FTI-L [mm] & $170.4 \pm 12.8$ & $176.5 \pm 13.2$ & 0.1 & $167.7 \pm 19.3$ & $165.8 \pm 19.1$ & 0.73 \\
\hline FTI-L [mm] & $77.8 \pm 10.7$ & $74.5 \pm 8.7$ & 0.24 & $74.7 \pm 9.2$ & $73.3 \pm 9.7$ & 0.6 \\
\hline Level of FT begin & $\mathrm{L} 1-2 \pm 2.2$ & $\mathrm{~L} 1-2 \pm 1.6$ & 0.2 & $\mathrm{~L} 1-2 \pm 2.7$ & $\mathrm{~L} 1 \mathrm{~L} \pm 2.1$ & 0.63 \\
\hline FT piercing level & $\mathrm{S} 2 \mathrm{U} \pm 1.98$ & $\mathrm{~S} 2 \mathrm{U} \pm 2.2$ & 0.4 & $\mathrm{~S} 2 \mathrm{M} \pm 1.8$ & $\mathrm{~S} 2 \mathrm{U} \pm 1.8$ & 0.54 \\
\hline Initial diameter (D1) & $1.59 \pm 0.23$ & $1.6 \pm 0.21$ & 0.87 & $1.54 \pm 0.22$ & $1.52 \pm 0.25$ & 0.77 \\
\hline Midpoint diameter (D2) & $0.87 \pm 0.21$ & $0.86 \pm 0.18$ & 0.86 & $0.91 \pm 0.20$ & $0.91 \pm 0.28$ & 1.0 \\
\hline Diameter at mid-FTE (D3) & $0.51 \pm 0.15$ & $0.42 \pm 0.12$ & $0.02^{*}$ & $0.45 \pm 0.15$ & $0.44 \pm 0.11$ & 0.79 \\
\hline
\end{tabular}

FT — filum terminale; FTE — filum terminale externum; FTI — filum terminale internum; *Significant difference between G1 and G2 at $p<0.05$ of each sex

\section{RESULTS}

MRI radiological parameters

The mean age of the two male groups was $32.6 \pm 6.8$ and $50.4 \pm 7.7$ years. No sex or age differences were observed in FT parameters, where in the two age groups of the male subjects, the mean length of FTI was $170.4 \pm 12.8 \mathrm{~mm}$ and $176.5 \pm 13.2 \mathrm{~mm}$. However, the mean length of FTE was $77.8 \pm 10.7 \mathrm{~mm}$ and $74.5 \pm 8.7 \mathrm{~mm}$. Moreover, the vertebral levels of initial point (CMT) and dural piercing (DST) of FT were observed at L1-2 disc and S2U segment in both age groups. Meanwhile, in female age groups, the mean length of FTI was $167.7 \pm 19.3 \mathrm{~mm}$ and $165.8 \pm$ $\pm 19.1 \mathrm{~mm}$. Also, the mean length of FTE was $74.7 \pm$ $\pm 9.2 \mathrm{~mm}$ and $73.3 \pm 9.7 \mathrm{~mm}$. However, the mean vertebral level of FT initiation was reported at L1-2 and L1L. Also, the mean of the dural piercing level of FT was S2M in the first age group and S2U in the second female age group. The diameters of FT at its initial point, midpoint and FTE-middle point were almost equal in both female age groups (Table 1 ).

In MRI measurements, the mean of the total length of FT was $246.6 \pm 18.7 \mathrm{~mm}$ in males and $241.5 \pm$ $\pm 20.5 \mathrm{~mm}$ in females $(p=0.02)$. Also, the mean length of FTI measured $174.1 \pm 16.8 \mathrm{~mm}$ in males and $166.9 \pm 18.9 \mathrm{~mm}$ in females $(p=0.06)$. However, the other parameters of FT of males including FTE length, level of begin, level of dural piercing, and the diameter at different three levels showed no significant difference ( $p>0.05$ ) compared to that of females, where the mean length of FTE measured $75.8 \pm 9.5 \mathrm{~mm}$ in males and $74.1 \pm 9.3 \mathrm{~mm}$ in females; the initial diameter was $1.6 \pm 0.22 \mathrm{~mm}$ in male and $1.53 \pm 0.25 \mathrm{~mm}$ in females; the midpoint-diameter was $0.86 \pm 0.2 \mathrm{~mm}$ in males and $0.91 \pm 0.23 \mathrm{~mm}$ in females and the diameter at mid-FTE was $0.46 \pm 0.14 \mathrm{~mm}$ in males and $0.45 \pm 0.13 \mathrm{~mm}$ in females $(p>0.05)$ (Table 2 ).

\section{Morphometric parameters of cadaveric FT}

The mean cadaveric height was $169.8 \pm 7.8 \mathrm{~cm}$ in male, $161.4 \pm 6.1 \mathrm{~cm}$ in female and $167 \pm 8.2 \mathrm{~cm}$ in all cadavers. The mean length of FT in male cadavers was $210.9 \pm 18.5 \mathrm{~mm}$ and in female cadavers was $187 \pm 16.8 \mathrm{~mm}(p=0.04)$. Also, the mean length of FTI in male cadavers was $164.2 \pm 11.6 \mathrm{~mm}$ and that of female cadavers was $159.2 \pm 10.1 \mathrm{~mm}(p>0.05)$. However, mean length of FTE in male cadavers measured $76.7 \pm 8.1 \mathrm{~mm}$ and $71.02 \pm 7.3 \mathrm{~mm}$ in female cadavers $(p=0.14)$. Moreover, no sex difference was recorded regarding the vertebral level of the initial point of FT (CMT) and dural sac piercing, where it was seen at $L 1 L$ and $\mathrm{S} 2 \mathrm{U}$ respectively in both sexes. However, a significant difference was recorded between the initial diameter of FT and midpoint diameter. Also, the diameter at the middle of FTE revealed significant difference compared to that of the midpoint diameter of FT of same sex. Meanwhile, no sex difference was recorded in the different cadaveric diameters of FT ( $p>0.05$ ) (Table 3 ).

\section{Differences between cadaveric and MRI radiological findings}

A significant difference $(p<0.05$ ) was recorded in the cadaveric mean length of FT, FTI and midpoint diameter compared to that of the MRI cases. However, no significant difference $(p>0.05)$ was recorded in the mean of body height, FTE length, initial and 
Table 2. Magnetic resonance imaging measurements of filum terminale in all males and females

\begin{tabular}{lcccc}
\hline & All males & All females & P & Total \\
\hline Age [year] & $40.1 \pm 11.6$ & $43.2 \pm 11.9$ & 0.19 & $41.9 \pm 12.1$ \\
Body length [cm] & $169.4 \pm 6.3$ & $164 \pm 7.3^{\mathrm{c}}$ & 0.001 & $166.7 \pm 7.3$ \\
FT-L [mm] & $245.6 \pm 18.7^{+}$ & $241.5 \pm 20.6^{+}$ & 0.3 & $248.2 \pm 23.4$ \\
FTI-L [mm] & $174.1 \pm 16.8^{+, \mathrm{a}, \mathrm{c}}$ & $166.9 \pm 18.9^{+, \mathrm{a}, \mathrm{c}}$ & 0.047 & $172.5 \pm 20.6$ \\
FTE-L [mm] & $75.8 \pm 9.5^{+, \mathrm{a}, \mathrm{b}}$ & $74.1 \pm 9.3^{+, \mathrm{ab} b}$ & 0.37 & $75.8 \pm 10$ \\
Level of FT begin & $\mathrm{L} 1-2 \pm 1.9$ & $\mathrm{~L} 1-2 \pm 2.4$ & 0.76 & $\mathrm{~L} 1-2 \pm 2.1$ \\
FT dural piercing level & $\mathrm{S} 2 \mathrm{U} \pm 2.1$ & $\mathrm{~S} 2 \mathrm{M} \pm 1.85$ & 0.3 & $\mathrm{~S} 2 \mathrm{U} \pm 2$ \\
Initial diameter (D1) & $1.6 \pm 0.21$ & $1.53 \pm 0.25$ & 0.13 & $1.59 \pm 0.26$ \\
Midpoint diameter (D2) & $0.86 \pm 0.2^{*}$ & $0.91 \pm 0.23^{*}$ & 0.25 & $0.89 \pm 0.21^{\mathrm{a}}$ \\
Mid-FTE diameter (D3) & $0.46 \pm 0.14^{*, * *}$ & $0.45 \pm 0.13^{* * * *}$ & 0.71 & $0.45 \pm 0.13^{\mathrm{a}, \mathrm{b}}$ \\
\hline
\end{tabular}

FT - filum terminale; FTE - filum terminale externum; FTI — filum terminale internum; $\left({ }^{+}\right)$Significant difference at $p<0.001$ vs. body length in individuals of the same sex; (a) Significant difference at $p<0.001$ vs. FTL in individuals of the same sex; (b) Significant difference at $p<0.001$ vs. FTI in individuals of the same sex; ( $\left(^{(}\right)$Significant difference vs. other sex at $p<0.05 ;\left(^{*}\right)$ Significant difference at $p<0.0$ vs. D1 in the same column; $\left({ }^{* *}\right)$ Significant difference at $p<0.01$ vs. D2 in the same column

Table 3. Measurements of filum terminale in all male and female cadavers

\begin{tabular}{lcccc}
\hline & Males $(\mathbf{n}=\mathbf{~ 1 5})$ & Females $(\mathbf{n}=\mathbf{1 0})$ & P & All cadavers $(\mathbf{n}=\mathbf{2 5})$ \\
\hline Age [year] & $47.2 \pm 11.4$ & $49 \pm 8.8$ & 0.68 & $47.9 \pm 10.3$ \\
Body length [cm] & $169.8 \pm 7.8$ & $161.4 \pm 6.1$ & $0.009^{c}$ & $167 \pm 8.2$ \\
FT-L [mm] & $210.9 \pm 18.5^{+, \mathrm{c}}$ & $187 \pm 16.8^{+, \mathrm{c}}$ & $<0.003^{\mathrm{c}}$ & $202.9^{\mathrm{c}} \pm 20.9^{+}$ \\
FTI-L [mm] & $164.2 \pm 11.6^{+}$ & $159.2 \pm 10.1^{+}$ & 0.28 & $162.3 \pm 12.8^{+}$ \\
FTE-L [mm] & $76.7 \pm 8.1^{+, \mathrm{a}, \mathrm{b}}$ & $71.02 \pm 7.3^{+, \mathrm{a}, \mathrm{b}}$ & 0.45 & $74.8 \pm 8.1^{+, \mathrm{a}, \mathrm{b}}$ \\
Level of FT begin (CMT) & $\mathrm{L} 1 \mathrm{~L} \pm 1.4$ & $\mathrm{~L} 1 \mathrm{~L} \pm 1.1$ & 0.78 & $\mathrm{~L} 1 \mathrm{~L} \pm 0.3$ \\
FT dural piercing level & $\mathrm{S} 2 \mathrm{U} \pm 2.2$ & $\mathrm{~S} 2 \mathrm{U} \pm 2.2$ & 0.87 & $\mathrm{~S} 2 \mathrm{U} \pm 2.1$ \\
Initial diameter (D1) & $1.7 \pm 0.14$ & $1.6 \pm 0.29$ & 0.26 & $1.7 \pm 0.2$ \\
Midpoint diameter (D2) & $0.74 \pm 0.13^{*}$ & $0.74 \pm 0.17^{*}$ & 1.00 & $0.74 \pm 0.14^{*}$ \\
Mid-FTE diameter (D3) & $0.45 \pm 0.14^{*}, \mathrm{~d}$ & $0.53 \pm 0.14^{*, \mathrm{~d}}$ & 0.17 & $0.48 \pm 0.14^{*, \mathrm{~d}}$ \\
\hline
\end{tabular}

FT - filum terminale; FTE - filum terminale externum; FTI - filum terminale internum; $\left({ }^{+}\right)$Significant difference at $p<0.001$ vs. body length in individuals of the same sex; $\left({ }^{\text {a }}\right)$ Significant difference at $p<0.001$ vs. FTL in individuals of the same sex; (b) Significant difference at $p<0.001$ vs. FTl in individuals of the same sex; $\left({ }^{(}\right)$Significant difference vs. other sex at $p<0.05$; (d) Significant difference at $p<0.01$ vs. D2 in the same column; ( $\left.{ }^{*}\right)$ : Significant difference at $p<0.0$ vs. D1 in the same column

mid-FTE diameters of cadaveric specimens compared to that of the MRI subjects. Moreover, low-laying fila below L2 were seen in $8 \%$ of cadaveric specimens and $5 \%$ of MRI subjects. In addition, the initial diameter of FT $>2 \mathrm{~mm}$ (thick fila) was recorded in $8 \%$ of cadaveric specimens and $7 \%$ of MRI subjects (Table 4).

\section{Histological findings}

The light microscopic examination of the lower conus (Fig. 4A-C) showed an excessive amount of glial cells, nerve cells (arrow), bundles of nerve fibres (N) and diffuse collagen fibres (F) scattering all over the section with small blood vessels in-between (BV); astrocytes - short arrow. The conus section was surrounded by a thick layer of dura mater (D) that contained an excessive amount of fibrous tissues (F) and many large-sized congested blood vessels (BV). Silver-stained section (Fig. 4B) revealed black-coloured nerve cells and brown-coloured diffuse collagen fibres with small blood vessels (BV) in-between. Large-sized blood vessels and excessive amount of fibrous tissues were seen within the thick dura (D). Masson trichrome stained section of conus (Fig. 4C) showed a positive reaction within the fibrous tissue $(F)$ of the dura mater (D), around the blood vessels (BV), and the stroma of the conus. A central canal (C) was seen within the middle of the section.

The histological structure of upper segment of FT (Fig. 4D-F) showed scattered groups of nerve cells and fibres $(N)$ within the peripheral zone of the section and excessive amount of collagen fibres (F) diffuse throughout the section with few small-sized blood 
Table 4. Comparative morphometric parameters of filum terminale in cadavers and magnetic resonance imaging (MRI) scans

\begin{tabular}{lcc}
\hline & Cadaveric specimens & MRI scans \\
\hline Mean age [years] & $47.9 \pm 10.3(28-68)$ & $41.9 \pm 12.1(21-60)^{*}$ \\
Sex (male/female) & $15 / 10$ & $50 / 50$ \\
Mean height (range) [cm] & $167 \pm 8.2(152-178)$ & $166.7 \pm 7.3(150-182)$ \\
Mean FT length (range) [mm] & $202.9 \pm 20.9(184-266)$ & $248.2 \pm 23.4(198-285)^{* *}$ \\
Mean FTl length (range) & $162.3 \pm 12.8(140-195)$ & $172.5 \pm 20.6(133-200)^{*}$ \\
Mean FTE length (range) & $74.8 \pm 8.1(60-89)$ & $75.8 \pm 10(50-90)$ \\
Mean initial point diameter (D1) & $1.7 \pm 0.2(1.4-2.2)$ & $1.59 \pm 0.26(0.93-2.3)$ \\
Mean mid-point diameter (D2) & $0.74 \pm 0.14(0.49-1.2)$ & $0.89 \pm 0.21(0.61-1.62)^{*}$ \\
Mean mid-FTE diameter (D3) & $0.48 \pm 0.14(0.25-0.7)$ & $0.45 \pm 0.13(0.22-0.79)$ \\
Low-laying fila, below L2 & $2(8 \%)$ & $5(5 \%)$ \\
Fila with initial diameter $>$ 2 mm & $2(8 \%)$ & $7(7 \%)$ \\
\hline
\end{tabular}

FT — filum terminale; FTE — filum terminale externum; FTI — filum terminale internum; *Significant difference between cadavers and MRI at $p<0.05 ;{ }^{* *}$ Significant difference between cadavers and MRI at $p<0.01$.

vessels (BV) in-between. Groups of ganglia (G) were seen at the peripheral zone of the section as well. A centrally located narrow canal (C) was seen within the section. Silver stained section (Fig. 4E) showed brown-stained diffuse collagen fibres (F), few nerve cells and little amount of nerve bundles $(N)$, groups of peripheral Ganglia (G) and blood vessels (BV). Masson trichrome stained section (Fig. 4F) revealed positive reaction (R) around the blood vessels (BV), between the nerve bundles $(\mathrm{N})$, and at the fibrous tissue of the thin pia mater around the section.

The histological structure of the middle part of FT (Fig. 4G-I) showing excessive amount of the diffuse collagen fibres (F), a few scattered small-sized blood vessels (BV) and little amount of nerve cells and fibres (N) in the peripheral zone. Psammoma-like structure $(* *)$ was seen under the thin pia mater as homogenous structure less mass. Silver stained section (Fig. 4H) showed the distribution of the collagen fibres (F) and the nerve bundle $(\mathrm{N})$ with blood vessels (BV) in-between. Masson trichrome-stained section (Fig. 4I) showed a positive reaction (R) around the blood vessels (BV) and within the thin pia and the collagenous stroma.

The light microscopic examination of the distal part of FT (FTE) (Fig. 4J-L) showed a very thin section consisting mainly of diffuse collagen fibres (F) and one or two small-sized blood vessels (BV) under the thin pia mater. Silver stained section (Fig. 4K) revealed the diffusely distributed collagen fibres (F) all over the section. Masson trichrome stained section (Fig. 4L) showed a positive reaction $(R)$ within the peripheral pia mater and within the stroma between the collagen fibres (F).

\section{DISCUSSION}

Filum terminale is fibrovascular band connecting $\mathrm{CM}$ with the coccyx. It consists of intradural and extradural parts. The intradural segment (FTI) extends CMT to DST. The extradural part (FTE) extends from DST to the coccygeal periosteum [6, 24].

In the present study, age and sex effect on the morphometric parameters and histological structure of normal FT were investigated by using adult human cadavers and MRI scans. Compared with the morphological measurements of the present study, minimal variations and minor differences were found in the morphometric parameters of FT in the previous cadaveric studies, where the mean length of FTI varied from $155.4 \mathrm{~mm}$ to $158.8 \mathrm{~mm}[6,9,16]$, while it measured $164.2 \pm 11.6 \mathrm{~mm}$ in male, $159.2 \pm$ $\pm 10.1 \mathrm{~mm}$ in female and $162.3 \pm 12.8 \mathrm{~mm}$ in all cadavers $(p>0.05)$ in the this study. Also, the mean of FTE length varied from $7-8 \mathrm{~cm}$ and its range was $14.5-18.5 \mathrm{~cm}$ in the previous cadaveric studies $[6,24]$. This difference might be due to the preservation process or the number the cadavers used.

The results of present research were in line with those of Pinto et al. [16] and De Vloo et al. [6] who found no significant correlation between the body length and FTI length. Contrary to Pinto et al. [16], the results of this investigation and those of De Vloo et al. [6] revealed a significant correlation between FTI length and DST level but no significant correlation 

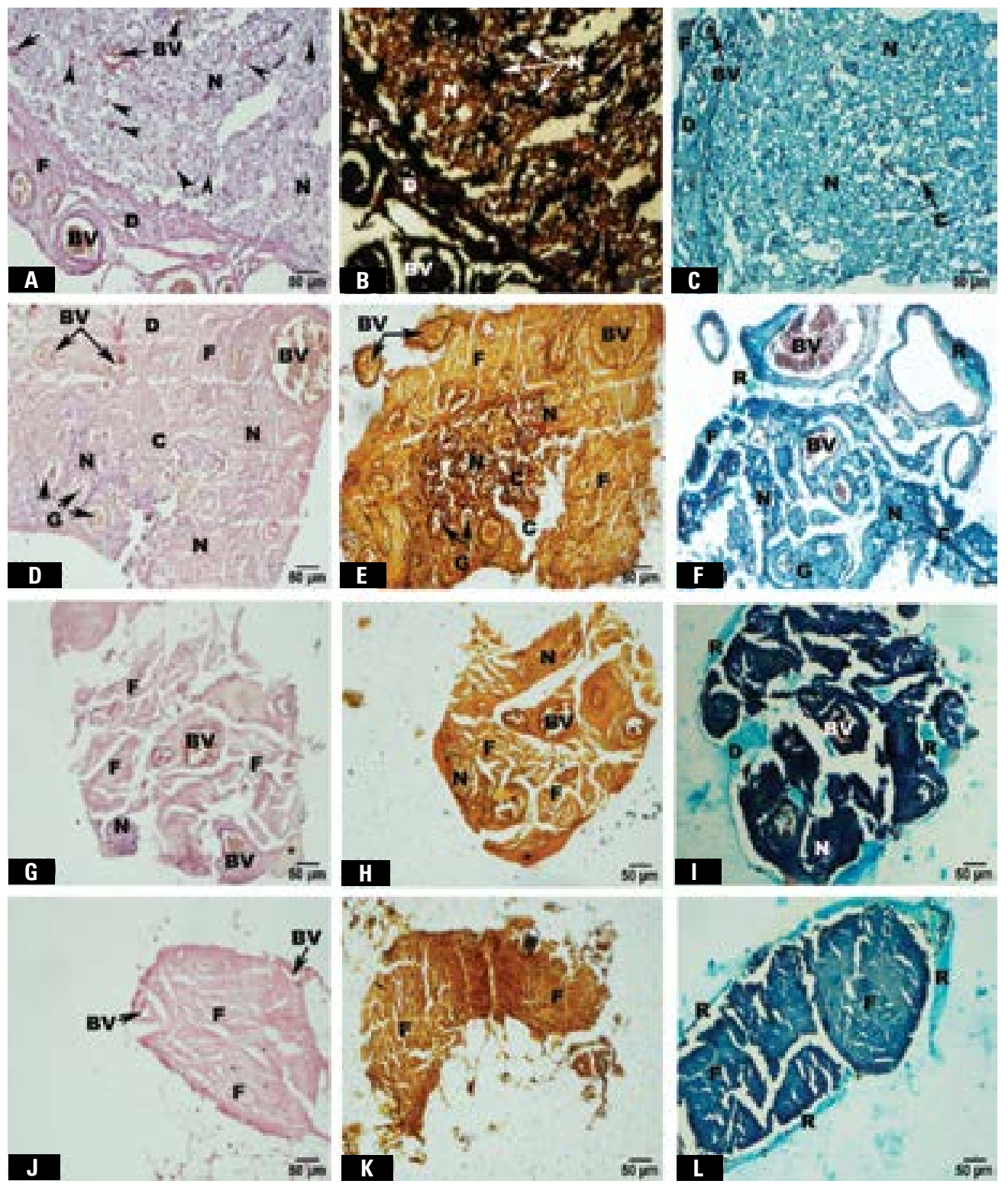

Figure 4. A. Light microscopic photographs of adult human filum terminale; A. Histological structure of lower conus medullaris showing scattered groups of nervous (N), glial (arrow heads), diffuse collagenous (F) structures with many small blood vessels (BV) in between. The thick pia (D) is composed of excessive fibrous structure (F) and many large congested blood vessels (BV); B. Silver stained-section of conus medullaris showing the black nerve cells (N), collagen fibres (F), thick pia (D) and wide blood vessels (BV); C. Masson trichrome-stained section of lower conus shows the positive reaction $(R)$ of collagen fibres $(R)$ within the pia; $\mathbf{D}$. A section of the upper part of intradural filum showing peripheral groups of nerve fibres and cells $(N)$, ganglion cells $(G)$, small blood vessels (BV) and diffuse collagen fibres (F) within the stroma and pia (D); E. Silver stained-section of the upper part of filum showing the distribution of nervous structure (N), collagenous structure $(\mathrm{F})$ and blood vessels (BV) within the segment; $\mathbf{F}$. Masson trichrome-stained section of the upper part of filum terminale showing the positive reaction $(R)$ of collagen fibres $(F)$ around blood vessels $(B V)$, nerve bundles $(N)$, ganglionic cells $(G)$ and at the thin pia; $\mathbf{G}$. Haematoxylin and eosin-stained section of the middle part of filum terminale showing few small blood vessels (BV), small peripheral nerve bundles (N) and excessive amount of fibrous structure $(\mathrm{F}) ; \mathbf{H}$. Silver stained section of the middle part of filum terminale showing the distribution of nerve bundle $(N)$, blood vessels $(B V)$ and collagen fibres $(F)$; I. Masson trichrome-stained section of a middle part of filum terminale showing the reaction (R) of collagen fibres (F) around the blood vessels (BV) and at the thin pia (D); J. Haematoxylin and eosin section of the lower segment of filum terminale showing its structure from collagen fibres (F) and few blood vessels (BV); K. Silver-stained section of a lower segment of the filum terminale shows excessive amount of collagen fibres (F) within the stroma; L. Masson trichrome-stained section of a lower segment of filum terminale shows the positive (R) within the fibrous stroma (F) and in the pia.

was recorded between the length of $\mathrm{FTI}$ and length of FTE or between initial level vertebral of FT (CMT) and DST levels. Also, in consistence with De Vloo et al. [6], a significant correlation was found between FTE length and body length. Thus, the vertebral level of the terminal end of FTE seemed to be more stable 
than that of the CMT and DST and the taller people had longer FTEs and higher DST level. So, the length FTE could compensate the level of DST [6].

In present work, the mean initial diameter of cadaveric $\mathrm{FTI}$ was $1.7 \pm 0.14 \mathrm{~mm}$ in male, $1.6 \pm 0.29 \mathrm{~mm}$ in female and $1.7 \pm 0.2 \mathrm{~mm}$ in all cadavers with no sex difference. In contrary to the findings of this study, lower and higher values of FT initial diameter were reported $[6,9,16]$. Two cadavers $(8 \%)$ of the present study, $4(10 \%)$ cadavers of Pinto et al. [16], and $6(30 \%)$ cadavers of De Vloo et al. [6] showed thick initial diameter of FT ( $>2 \mathrm{~mm}$ ). In agree with Pinto et al. [16], a significant correlation was found between the initial diameter of FT and its midpoint-diameter but not between initial diameter and the diameter at the middle of FTE. These findings reinforce the idea that the thickness of FT is uniform and decrease along its length toward the end of dural sac. However, De Vloo et al. [6] found a significant correlation between FTE diameter and the between the caudal FTI diameters, but not between the initial diameter of FTI and the other FTI diameters. Thus, the initial diameter of FT was not a good measurement of all diameters of FTI, while the midpoint diameter could be considered the better criterion for TCS than the initial diameter of FTI [6].

In agree with the results of this study, De Vloo et al. [6], stated that the mean of beginning level of FT was L1L vertebra and that of the initial point was observed below L2 in 2 (8\%) cadavers. However, Pinto et al. [16], found the mean vertebral level of the initial point of $\mathrm{FT}$ at L1M with 2 cadavers having lower level (below L2). In consistence with results of present work, dural fusion of FT was comely seen at S2, but in $15 \%$ to $30 \%$ of the cadavers demonstrated fila that fused above S2 $[6,9,16]$. These data should be remembered during surgical intervention for TCS management through $\mathrm{S} 1$ laminectomy for sectioning FT. No sex differences were recorded in the parameters of FT in the other cadaveric study.

Magnetic resonance imaging is a non-invasive radiological method to demonstrate the anatomy of the lumbosacral region in subjects whose scans showing disorders could be excluded. In the present study, all MRI morphometric parameters of FT revealed no sex difference in the two different age groups. No research was carried out on the MRI parameters of normal FT at adult age in both sexes. So this study is unique in this field. Only, the level of CMT and DST in both male and female subjects was reported in literature $[10,15,20]$. In this study, the MRI range of the initial thickness of FT was $0.93-2.3 \mathrm{~mm}$ and its mean was $1.6 \pm 0.26$. Moreover, the vertebral level of the initiation of FT (CMT) ranged from T12L to L3U and its mean was L1-2 disc, only 5\% below L2.

Moreover, the vertebral level of FT piercing to dural sac (DST) ranged from L5-S1-S3U and its mean was S2U. Only $15 \%$ were recorded at S1 or above. Also, the mean length of FTI was $172.5 \pm 20.6 \mathrm{~mm}$ and its range was $133-200 \mathrm{~mm}$ with significant sex difference $(p<0.05)$, while that of FTE was $75.8 \pm$ $\pm 10 \mathrm{~mm}$ and its range was $50-95 \mathrm{~mm}$ with no sex difference $(p>0.05)$. The parameters of FT in the present research revealed no sex or age differences $(p>0.05)$. Contrary to the results of the present research, other authors found the mean level of CMT at L1 L or above with no sex or age significant difference $[5,10,19]$. However, in agreement with the results of this study, Soleiman et al. [19] and Barum et al. [3] found the mean vertebral level of DST (dural piercing level of FT) at S2U with no significant sex difference, but with variable range. This discrepancy might be due to racial difference, numerical difference or/and technique used in the study.

Understanding the pathophysiology of TCS helps neurosurgeons to manage its clinical manifestations [25]. The presenting symptoms of TCS include neurological manifestations, urodynamic dysfunction and gait disturbance. FT thickness more than $2 \mathrm{~mm}$ and/ /or location of CMT below L2 were considered the MRI diagnostic criteria in cases presenting with symptoms of TCS $[1,24]$. Regarding these two parameters, $12 \%$ of the cases revealed one diagnostic criterion of TCS in this study. However, in some cases, the clinical presentations must be combined with these radiological criteria to clinch the diagnosis of TCS $[8,18]$. So, the occurrence of symptomatic TCS might be related to another factor.

The structure of FT is not a simple fibrovascular cord, but a complex tridimensional structure [11]. In accordance with the findings of this research, the normal FT consisted mainly of loose collagen fibres, nerve fascicles, small blood vessels, ependymal cells lining remnants of the central canal, while with dense collagen fibres, excessive amount of fibrous connective tissue, dilated capillaries, random fat cells, and areas of hyalinisation were seen in the abnormal fila with symptomatic TCS [17]. Moreover, the histological structure of the normal FT was composed of fibrous connective tissue, peripheral nerves, adipose tissue and neuroglial 
tissue [4]. These results were in consistence with those of present study, but no adipose tissue was observed within the structure of normal FT. Contrary to the findings of present study, Tubbs et al. [24] found smooth muscle, bone and cartilages cells within the FTE.

The elastic property of FT had a role in pathology, diagnosis, and treatment of TCS $[8,11]$. Presence of excessive amount of fibrous tissues within the structure of FT (inelastic) could induce abnormal traction on the spinal cord with subsequent vascular, biomechanical, biochemical, and molecular changes. As a result, the buffer-like action of FT in the traction forces applied at the caudal spinal cord decreased with consequent occurrence of TCS $[8,17]$. Thickening, distortion, adhesion or fusion of collagen fibres with invisible elastic and fibrillary fibres were seen in FT of TCS. These changes induced loss of elasticity and structural deterioration of FT of TCS [12]. However, no elastic fibres were seen in foetal FT, but became visible after birth. So, the quantitative variation of elastic fibres had a share in the development of TCS during childhood and adulthood [23]. Sometimes, disturbed collagenous structure, reduced elasticity and hyalinisation were observed in normal-appearing FT [17]. So, in addition to traction effect, the structural abnormalities in FT were responsible for TCS in children [18].

Similar to results of this study, glial cells and neural components with residue of the central canal were found in the structure of normal FT [23]. However, Tubbs et al. [24] found thin, sparsely cellular fibrous bands, Psammoma-like calcifications, and smooth-muscle bundles within the fibrous stroma, small twigs of peripheral nerves, adipose tissue, straight blood vessels, and few ganglia in the proximal FTE. The author added that, no glial or ependymal cells were seen in FTE. In contrary to Tubbs et al. [24], no adipose tissue or smooth muscle bundles were observed in FTE of the present study.

The vascular, biomechanical, biochemical and molecular changes in FT of TCS should be further investigated to clear the pathophysiology of TCS and improve its clinical manifestations [7, 8, 23]. Further investigation should be done to assess the amount of fibrous, adipose, vascular, and nervous tissues in normal adult fila and comparing them with the fila of TCS.

\section{CONCLUSIONS}

The FT is not a simple fibrovascular band but a complex structure containing elastic fibres, excessive amount of loose collagen fibres, few blood vessels, glial cells and small fascicules of nerves. Histopathology is more sensitive in detecting the structural changes in FT than MRI. Thus, by both MRI and histological examination we can detect any structural alterations of FT, may be involved in TCS, which has great clinical significance especially for treatment of TCS with normal conus position.

\section{Acknowledgements}

Great appreciations to all technicians of the Anatomy Department, Faculty of Medicine, King Abdulaziz University for their help during doing this study.

\section{REFERENCES}

1. Aggarwal A, Kaur H, Batra YK, et al. Anatomic consideration of caudal epidural space: a cadaver study. Clin Anat. 2009; 22(6): 730-737, doi: 10.1002/ca.20832, indexed in Pubmed: 19637298.

2. Bancroft JD, Gamble M. Theory and practice of histological techniques. 5th ed. Edinburgh. New York, London, Philadelphia Churchill Livingstone. 2002. 125-138, 172-175, 184-193, 593-620.

3. Barun KS, Rubi D, Sumit K, et al. magnetic resonance imaging study of the variations of position of conus medullaris and thecal sac in the adult population in Sikkim. Indian J Clin Anat Physiology. 2017; 4(1): 8-10.

4. Cummings T, George T. The Immunohistochemical Profile of the Normal Conus medullaris and Filum terminale. Neuroembryology. 2003; 2(2): 43-49, doi: 10.1159/000071020.

5. Demiryürek $D$, Aydingöz U, Akşit MD, et al. MR imaging determination of the normal level of conus medullaris. Clin Imaging. 2002; 26(6): 375-377, indexed in Pubmed: 12427430.

6. De Vloo P, Monea AG, Sciot $R$, et al. The filum terminale: a cadaver study of anatomy, histology, and elastic properties. World Neurosurg. 2016; 90: 565-573.e1, doi: 10.1016/j. wneu.2015.12.103, indexed in Pubmed: 26805693.

7. Eric TM, Michael SJ, Garth W, et al. Clinical significance of imaging and histological characteristics of filum terminale in tethered cord syndrome. J Neurosurg Pediatr. 2014; 13(3): 255-259, doi: 10.3171/2013.12.PEDS13370, indexed in Pubmed: 24404969.

8. Filippidis AS, Kalani MY, Theodore N, et al. Spinal cord traction, vascular compromise, hypoxia, and metabolic derangements in the pathophysiology of tethered cord syndrome. Neurosurg Focus. 2010; 29(1): E9, doi: 10.3171/2010.3.FOCUS1085, indexed in Pubmed: 20594007.

9. Fontes RBV, Saad F, Soares MS, et al. Ultrastructural study of the filum terminale and its elastic fibers. Neurosurgery. 2006; 58(5): 978-984; discussion 978, doi: 10.1227/01. NEU.0000210224.54816.40, indexed in Pubmed: 16639335.

10. Karabulut O, Akay H, Karabulut Z, et al. Conus medullaris position in an adult population: analysis of magnetic resonance imaging. Int J Morphol. 2016; 34(4): 1352-1356, doi: 10.4067/s0717-95022016000400029.

11. Li J, Zhang J, Guan X, et al. Scanning electron microscopy (SEM) study on filum terminale with human fetus. Int J Clin Exp Med. 2016; 9(2): 3118-3124. 
12. Liu FY, Li JF, Guan X, et al. SEM study on filum terminale with tethered cord syndrome. Childs Nerv Syst. 2011; 27(12): 2141-2144, doi: 10.1007/s00381-011-1414-0, indexed in Pubmed: 21387201.

13. Moore KL, Persaud TVN, Mark G. Torchia. The developing of human, clinically oriented embryology. 10th ed. Saunders. 2015.

14. Moussallem CD, El Masri H, El-Yahchouchi C, et al. Relationship of the lumbar lordosis angle to the level of termination of the conus medullaris and thecal sac. Anat Res Int. 2014; 2014: 351769, doi: 10.1155/2014/351769, indexed in Pubmed: 25101178.

15. Nasr AY, Nasr AY. Clinical relevance of conus medullaris and dural sac termination level with special reference to sacral hiatus apex: anatomical and MRI radiologic study. Anat Sci Int. 2017; 92(4): 456-467, doi: 10.1007/s12565016-0343-0, indexed in Pubmed: 27094162.

16. Pinto FC, Fontes RB, Leonhardt Md, et al. Anatomic study of the filum terminale and its correlations with the tethered cord syndrome. Neurosurgery. 2002; 51(3): 725-729; discussion 729, indexed in Pubmed: 12188951.

17. Selçuki $M$, Vatansever $S$, Inan $S$, et al. Is a filum terminale with a normal appearance really normal? Childs Nerv Syst. 2003; 19(1): 3-10, doi: 10.1007/s00381-002-0665-1, indexed in Pubmed: 12541079.

18. Selden NR, Nixon RR, Skoog SR, et al. Minimal tethered cord syndrome associated with thickening of the terminal filum. J Neurosurg. 2006; 105(3 Suppl): 214-218, doi: 10.3171/ ped.2006.105.3.214, indexed in Pubmed: 16970235.

19. Soleiman J, Demaerel P, Rocher S, et al. Magnetic resonance imaging study of the level of termination of the conus medullaris and the thecal sac: influence of age and gender. Spine (Phila Pa 1976). 2005; 30(16): 1875-1880, indexed in Pubmed: 16103859.

20. Soonwook Kwon, Kim T, Kim H, et al. The tip level of the conus medullaris by magnetic resonance imaging and cadaver studies in korean adults. Korean J Physical Anthropol. 2016; 29(2): 47-51, doi: 10.11637/ kjpa.2016.29.2.47.

21. Standring S. Standring S. Gray's Anatomy: The Anatomical Basis of Clinical Practice41st ednEdinburgh, London, New York, PhiladelphiaSydneyToronto: Churchill Livingstone Elsevier. 2016.

22. Stroman PW, Wheeler-Kingshott $C$, Bacon $M$, et al. The current state-of-the-art of spinal cord imaging: methods. Neuroimage. 2014; 84: 1070-1081, doi: 10.1016/j.neuroimage.2013.04.124, indexed in Pubmed: 23685159.

23. Tehli O, Hodaj I, Kural C, et al. A comparative study of histopathological analysis of filum terminale in patients with tethered cord syndrome and in normal human fetuses. Pediatr Neurosurg. 2011; 47(6): 412-416, doi: 10.1159/000338981, indexed in Pubmed: 22776912.

24. Tubbs RS, Murphy RL, Kelly DR, et al. The filum terminale externum. J Neurosurg Spine. 2005; 3(2): 149-152, doi: 10.3171/spi.2005.3.2.0149, indexed in Pubmed: 16370304.

25. Yamada S, Won DJ, Yamada SM, et al. Adult tethered cord syndrome: relative to spinal cord length and filum thickness. Neurol Res. 2004; 26(7): 732-734, doi: 10.117 9/016164104225017929, indexed in Pubmed: 15494113.

26. Yamada S, Won DJ, Pezeshkpour G, et al. Pathophysiology of tethered cord syndrome and similar complex disorders. Neurosurg Focus. 2007; 23(2): E6, doi: 10.3171/FOC07/08/E6, indexed in Pubmed: 17961011. 